\title{
Structure of Oligosaccharides Obtained by Hydrolysis of Mung Bean Xyloglucan with Trichoderma viride Cellulase*
}

\author{
Yoji Kato and Kazuo Matsuda \\ Department of Agricultural Chemistry, Faculty of Agriculture, \\ Tohoku University, Sendai 980, Japan
}

Received September 6, 1979

Three kinds of oligosaccharides, hepta-, nona- and deca-saccharides, were obtained by hydrolysis with Trichoderma viride cellulase from mung bean xyloglucan (MBXG) prepared from cell walls of etiolated mung bean hypocotyls. Structural formulas were proposed for the oligosaccharides from the results of methylation analyses and fragmentation analyses with Aspergillus oryzae $\beta$-glucosidase to be as follows:


In the previous work, ${ }^{1 \sim 31}$ we isolated and partially characterized a xyloglucan (MBXG) from cell walls of etiolated mung bean hypocotyls. It was suggested that MBXG consists of a cellulose-like main chain and side chains of single $\alpha$-D-xylopyranosyl residues and $\alpha$-L-fucopyranosyl-( $1 \rightarrow 2)-\beta$-D-galactopyranosyl- $(1 \rightarrow 2)-\alpha$-D-xylopyranosyl residues that are attached to the C-6 positions of the main chain. ${ }^{3)}$ This report deals with the determination of the probable structure of the oligosaccharides formed in the Trichoderma viride cellulase-hydrolyzate of MBXG.

\section{MATERIALS AND METHODS}

Materials. The MBXG used was the same as reported previously. ${ }^{3)}$ Tamarindus indica seed xyloglucan (amyloid) was purified via copper complex ${ }^{4}$ from "Glyloid 2A" (Dainippon Pharmaceutical Co., Ltd., Osaka, Japan)

\footnotetext{
* Structure of a Xyloglucan from Cell Walls of Etiolated Mung Bean Hypocotyls. Part II.
}

which was kindly provided by Mr. Y. Kumagai (Morinaga Seika Co., Ltd.). From the amyloid, three kinds of oligosaccharides, heptasaccharide (glucose : $x y l o s e=4: 3$ ), octasaccharide (glucose: xylose: galactose $=4: 3: 1$ ) and nonasaccharide (glucose: xylose : galactose $=4: 3: 2$ ) were prepared by cellulase-hydrolysis followed by fractionation with a Bio-Gel P-2 column $(1.5 \times 150 \mathrm{~cm})$. The detailed structures of the oligosaccharides were reported by Kooiman. ${ }^{5)}$ The cellulase preparation from Trichoderma viride was purchased from Seikagaku Kogyo Co., Ltd. It contained little xylanase, amylase and $\beta$-1,3-glucanase activities. Beta-glucosidase was partially purified from Aspergillus oryzae enzyme preparation (Sanzyme 1000) using salicin as a substrate by chromatographies using columns of alkaline-swollen cellulose powder, DEAESephadex A-50, Sephadex G-100 and Sephadex G-200. ${ }^{6}$ The partially purified $\beta$-glucosidase preparation is able to hydrolyze cellobiose, gentiobiose and laminaribiose. Furthermore, it hydrolyzes an oligosaccharide prepared from Tamarind amyloid, $\alpha$-D-Xyl- $(1 \rightarrow 6)-\beta$-D-Glc- $(1 \rightarrow 4)$ $[\alpha-D-X y]-(1 \rightarrow 6)]-\beta-D-G 1 \mathrm{c}-(1 \rightarrow 4)-[\alpha-D-X y 1-$ $(1 \rightarrow 6)]-\beta$-D-Glc- $(1 \rightarrow 4)$-D-Glc, which is not hydrolyzed by the $\beta$-glucosidase pareparation of Pyricularia oryzae ${ }^{7}$ or almond. The Asp. oryzae $\beta$-glucosidase preparation contained a little $\beta$-galactosidase activity, but was free from $\alpha$-galactosidase. 
General methods. All evaporations were carried out under reduced pressure at $40 \sim 45^{\circ} \mathrm{C}$. Paper chromatography was performed on Toyo No. 50 filter paper by an ascending method with solvent system (A); n-butanolpyridine-water $(6: 4: 3, \mathrm{v} / \mathrm{v})$. Neutral sugars were detected on the chromatogram by treatment with alkaline silver nitrate. ${ }^{8}$ Preparative paper chromatography was carried out on Toyo No. 50 filter paper by an ascending method with solvent system (A). Optical rotations were determined with a Nippon Bunko Model DIP-SL polarimeter. Gas-liquid chromatography was carried out with a Yanagimoto Model G-80 gas chromatography apparatus fitted with a flame ionization detector, using a glass column $(0.4 \times 200 \mathrm{~cm})$ packed with $1.5 \%$ QF-1 on Chromosorb W (column (a)), a glass column $(0.4 \times 200 \mathrm{~cm})$ packed with $10 \%$ poly(diethyleneglycol succinate) on Diasolid-L (column (b)) and a glass column $(0.4 \times 200 \mathrm{~cm})$ packed with $3 \%$ OV-210 on Supelcoport (column (c)).

Neutral sugar analysis of oligosaccharides. Oligosaccharides were hydrolyzed in sealed tubes with $1 \mathrm{~N}$ sulfuric acid for $3 \sim 4$ hr at $100^{\circ} \mathrm{C}$. The hydrolyzate was neutralized with barium carbonate, deionized with Amberlite IR-120 resin $\left(\mathrm{H}^{+}\right.$form), and evaporated to dryness. Monosaccharides in the hydrolyzates were converted into their corresponding alditol trifluoroacetates," and the derivatives were analyzed by gas chromatography using column (a).

Methylation analysis of oligosaccharides. Oligosaccharides $(1 \sim 2 \mathrm{mg})$ were methylated by the method of Hakomori. ${ }^{103}$ Sugar components of methylated oligosaccharides were analyzed as methylglycosides formed on methanolysis by gas chromatography using column (b), or as partially methylated alditol acetates formed on hydrolysis, followed by reduction with sodium borohydride and acetylation ${ }^{11}$ by gas chromatography using column (c). The partially methylated alditol acetate standards were prepared from Tamarind xyloglucan, pentasaccharide of $\mathrm{MBXG},{ }^{3)}$ laminaribiose, gentiobiose, cellobiose and others.

Degree of polymerization (D.P.) of oligosaccharides. To determine D.P. of oligosaccharides, each oligosaccharide ( $1 \sim 5 \mathrm{mg} / \mathrm{I} \mathrm{ml}$ water) was applied to a Bio-Gel P-2 column $(1.5 \times 150 \mathrm{~cm})$, followed by filtration with water. Fractions of $1 \mathrm{ml}$ were collected, and each fraction was assayed for the total sugar content by the phenol-sulfuric acid method. ${ }^{12}$ Calibration of D.P. was performed by using a mixture of authentic carbohydrates; glucose, various maltooligosaccharides (D.P. 2 9) and blue dextran.

Hydrolysis of oligosaccharides with Asp. oryzae $\beta$ glucosidase. Oligosaccharides $(0.2 \sim 2 \mathrm{mg})$ were dissolved in water $(1 \mathrm{ml})$ containing Asp. oryzae $\beta$-glucosidase preparation $(0.05 \sim 0.1 \mathrm{ml})$ and incubated at $40^{\circ} \mathrm{C}$ for $15 \mathrm{hr}$ under a covering of a few drops of toluene. After incubation, the reaction mixtures were heated in a boiling water bath for $10 \mathrm{~min}$, concentrated under reduced pressure to a small volume and subjected to paper chromatography using solvent system (A). The total sugar content of components in the hydrolyzate was determined by the phenol-sulfuric acid method ${ }^{12)}$ after separation by paper chromatography.

\section{RESULTS AND DISCUSSION}

\section{Hydrolysis of $M B X G$ with $T$. viride cellulase}

MBXG $(300 \mathrm{mg})$ was dissolved in water $(150 \mathrm{ml})$ and incubated with the cellulase $(4 \mathrm{mg})$ at $48^{\circ} \mathrm{C}$ for $72 \mathrm{hr}$. After the incubation, the solution was heated in a boiling water bath for $15 \mathrm{~min}$. A small quantity of insoluble material $(4.8 \mathrm{mg})$ was removed by centrifugation as a precipitate, and the supernatant solution was concentrated to a small volume, lyophilized and dissolved in water $(10 \mathrm{ml})$. Then gel filtration through a Bio-Gel P-2 column $(1.5 \times 145 \mathrm{~cm})$ was performed. The filtration pattern is shown in Fig. 1. Fraction Nos. 57 to 79 were combined and designated as the high molecular weight oligosaccharides fraction (H-OS). Fraction Nos. 80 to 105 were combined and designated as L-OS (low molecular weight oligosaccharides fraction). Both fractions were separately concentrated to a small volume and lyophilized. The yields of $\mathrm{H}$ -



Fig. 1. Fractionation of the Oligosaccharides Produced from MBXG by Cellulase Hydrolysis.

The reaction products $(2 \mathrm{ml})$ were loaded on a Bio-Gel P2 column $(1.5 \times 145 \mathrm{~cm})$, and fractionated by filtration with water. Each fraction was assayed for the total sugar content. Five such fractionations were performed. 

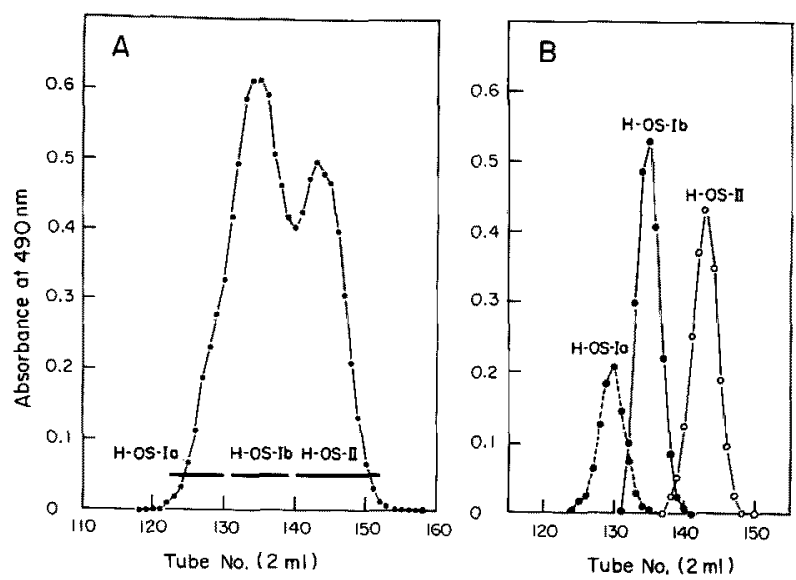

FIG. 2-A. Fractionation of H-OS.

H-OS ( $213 \mathrm{mg} / 2 \mathrm{ml}$ water) was applied to a Bio-Gel P-4 column $(2 \times 200 \mathrm{~cm})$ and fractionated by filtration with water. Each fraction was assayed for the total sugar content.

Fyg. 2-B. Elution Pattern of the Purified H-OS-Ia, -Ib and -II on a Column of Bio-Gel P-4.

Table I. Yrelds, Specific Optical Rotations and Sugar Compositions of the High Molecular Weight Oligosaccharide Fractions

\begin{tabular}{|c|c|c|c|c|c|c|}
\hline \multirow{2}{*}{ Fraction } & \multirow{2}{*}{$\begin{array}{l}\text { Yield } \\
\text { (mg) }\end{array}$} & \multirow{2}{*}[\alpha]{$_{D}$} & \multicolumn{4}{|c|}{ Molar ratio of component sugars } \\
\hline & & & Glc. & Xyl. & Gal. & Fuc. \\
\hline $\mathrm{H}-\mathrm{OS}-\mathrm{Ia}$ & 19.3 & $+44^{\circ}$ & 4.0 & 2.9 & 2.3 & 1.1 \\
\hline H-OS-Ib & 66.9 & $+54^{\circ}$ & 4.0 & 2.6 & 1.2 & 1.0 \\
\hline H-OS-II & 53.3 & $+80^{\circ}$ & 4.0 & 2.8 & & \\
\hline
\end{tabular}

(from $300 \mathrm{mg}$ of $\mathrm{MBXG}$ )

OS and L-OS were 213 and $45 \mathrm{mg}$, molar ratio of approximately $3: 4$ (Table I). respectively. This oligosaccharide appeared at the same filtration volume as that of the heptasac-

High molecular weight oligosaccharides fraction $(\mathrm{H}-\mathrm{OS})$

A mixture of high molecular weight oligosaccharides was fractionated by gel filtration through a Bio-Gel P-4 column (Fig. 2-A). Fraction Nos. 123 to 130,131 to 139 and 140 to 152 were separately combined, and designated as H-OS-Ia, -Ib and -II, respectively. Each fraction was purified by repeating the gel filtration until a single peak filtration pattern was obtained (Fig. 2-B). Table I shows yields, specific optical rotations and sugar compositions of the fractions.

H-OS-II consisted of xylose and glucose in a charide from $T$. indica amyloid on a Bio-Gel P2 column. Upon hydrolysis with $A s p$. oryzae $\beta$ glucosidase, H-OS-II yielded isoprimeverose and glucose in a molar ratio of approximately 3:0.9 (minor peaks in Fig. 3-(a) were considered to be due to incomplete hydrolysis). Methylation analysis showed that H-OS-II consisted of three non-reducing terminal xylose residues, one C-6-substituted glucose residue, one $\mathrm{C}$-4-substituted glucose residue and two 4,6-C-substituted glucose residues (Table II). Based on the results described above, the following structure is proposed for H-OS-II; 
Table II. Methylation Analysis of H-OS-II

\begin{tabular}{rccccc}
\hline & \multicolumn{2}{c}{ Alditol acetate } & & \multicolumn{2}{c}{ Methyl glycoside } \\
\cline { 2 - 4 } \cline { 5 - 6 } Derivatives $^{a}$ & $\mathbf{T}^{b}$ & Molar ratio & & $\mathbf{T}^{\mathrm{c}}$ & $\begin{array}{c}\text { Approximate relative } \\
\text { amounts }\end{array}$ \\
\hline $2,3,4-\mathrm{Me}_{3}-\mathrm{Xyl}$ & 0.69 & 3.1 & & $0.48,0.61$ & ++ \\
$2,3,4-\mathrm{Me}_{3}-\mathrm{Glc}$ & 2.37 & 2.0 & & $2.85,4.19$ & + \\
$2,3,6-\mathrm{Me}_{3}-\mathrm{Glc}$ & 2.37 & 2.0 & $3.80,5.33$ & + \\
$2,3-\mathrm{Me}_{2}-\mathrm{Glc}$ & 4.72 & & & - & + \\
\hline
\end{tabular}

a 2,3,4-Me $-\mathrm{Xyl}=2,3,4-$ tri- $O$-methyl-D-xylose and so on.

b Retention times of the corresponding alditol acetates on an $\mathrm{OV}-210$ column at $175^{\circ} \mathrm{C}$, relative to 1,5 -di- $O$-acetyl2,3,4,6-tetra- $O$-methyl-D-glucitol.

c Retention times of the corresponding methyl glycosides on a poly(diethyleneglycol succinate) column at $180^{\circ} \mathrm{C}$, relative to methyl-2,3,4,6-tetra- $O$-methyl- $\beta$-D-glucoside.



$\mathrm{H}$-OS-Ib consisted of fucose, galactose, xylose and glucose in a molar ratio of approximately $1: 1: 3: 4$ (Table I). This oligosaccharide appeared at the same filtration volume as that of the nonasaccharide from $T$. indica amyloid on a Bio-Gel P-2 column. The results of methylation analysis of this oligosaccharide are shown in Table III. H-OS-Ib, when hydrolyzed with Asp. oryzae $\beta$-glucosidase, yielded isoprimeverose and an oligosaccharide having an Rglc value of 0.24 (paper chromatography) in an approximate ratio of $1.1: 1.0$ (weight) (Fig. 3-(b)). The latter oligosaccharide was eluted from the paper chromatogram with deionized water and hydrolyzed with acid. Monosaccharides in the hydrolyzate were found to be glucose, xylose, galactose and fucose in an approximate molar ratio of $2: 1: 1: 1$. The D.P. of this oligosaccharide was calculated to be 5 by gel filtration through a Bio-Gel P-2 column. Our previous work $^{3)}$ showed that MBXG yilded two kinds of oligosaccharides, isoprimeverose (Rglc 0.75 ) and $\alpha$-L-fucosyl- $(1 \rightarrow 2)-\beta$-D-galactosyl- $(1 \rightarrow 2)$ $\alpha-\mathrm{D}-\mathrm{x}$ y los y $1-(1 \rightarrow 6)-\beta-\mathrm{D}-\mathrm{gl}$ ucosyl$(1 \rightarrow 4)$-D-glucose (Rglc 0.25 ), on hydrolysis with Asp. oryzae enzyme preparation (San-

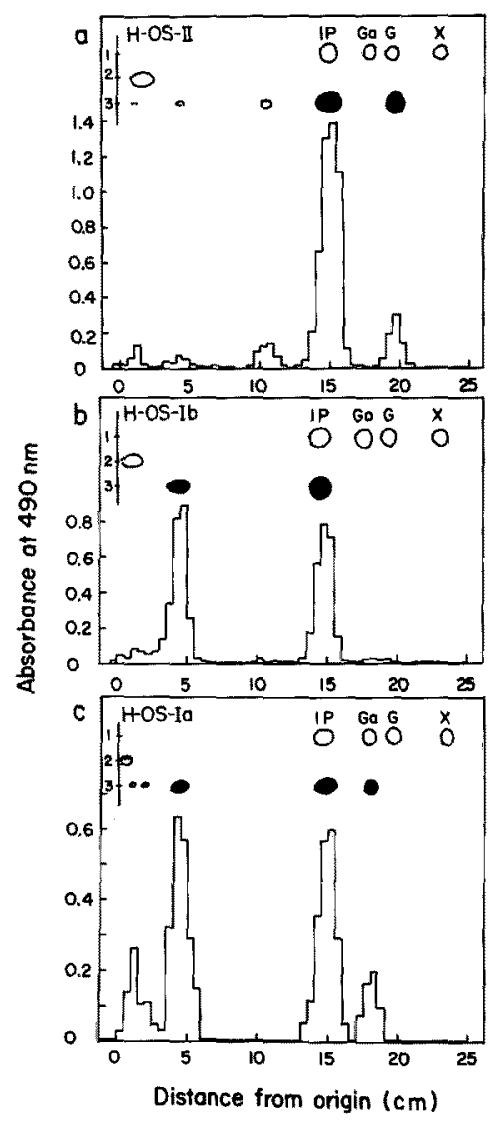

FIG. 3. Paper Chromatograms of the Hydrolyzates of H-OS-II, -Ib and -Ia with Asp. oryzae $\beta$-Glucosidase. 1 , authentic sugars; 2 , original oligosaccharide; 3 , hydrolyzate with $A$ sp. oryzae $\beta$-glucosidase. IP, Ga, G and $\mathrm{X}$ indicate the positions of isoprimeverose, galactose, glucose and xylose, respectively. 
Table III. Methylation ANalysis of H-OS-Ia AND H-OS-Ib

\begin{tabular}{|c|c|c|c|}
\hline \multirow{2}{*}{ Derivatives $^{a}$} & \multirow{2}{*}{$\mathrm{T}^{b}$} & \multicolumn{2}{|c|}{ Molar ratio } \\
\hline & & H-OS-Ia & $\mathrm{H}-\mathrm{OS}-\mathrm{Ib}$ \\
\hline $2,3,4-\mathrm{Me}_{3}-\mathrm{Fuc}$ & 0.72 & 1.1 & 0.9 \\
\hline $2,3,4-\mathrm{Me}_{3}-\mathrm{Xyl}$ & 0.69 & 1.1 & 1.6 \\
\hline 3,4-Me $-\mathrm{Xyl}$ & 1.47 & 2.2 & 1.2 \\
\hline $2,3,4,6-\mathrm{Me}_{4}-\mathrm{Gal}$ & 1.15 & 0.8 & 0.1 \\
\hline $3,4,6-\mathrm{Me}_{3}-\mathrm{Gal}$ & 2.24 & 1.1 & 0.9 \\
\hline $2,3,4-\mathrm{Me}_{3}$-Glc & 2.37 & & \\
\hline $2,3,6-\mathrm{Me}_{3}-\mathrm{Glc}$ & 2.37 & 1.8 & 2.2 \\
\hline 2,3-Me $-\mathrm{Glc}$ & 4.72 & 2.0 & 2.0 \\
\hline
\end{tabular}

a 2,3,4-Me $-\mathrm{Fuc}=2,3,4-\operatorname{tri}-O$-methyl-L-fucose and so on.

b Retention times of the corresponding alditol acetates on an OV-210 column at $175^{\circ} \mathrm{C}$, relative to $1,5-\mathrm{di}-\mathrm{O}$ acetyl-2,3,4,6-tetra- $O$-methyl-D-glucitol.

zyme 1000). Therefore, it is reasonable to consider that the pentasaccharide from $\mathrm{H}-\mathrm{OS}$ Ib is $\alpha$-L-fucosyl- $(1 \rightarrow 2)-\beta$-D-galactosyl- $(1 \rightarrow 2)$ $\alpha$-D-xylosyl- $(1 \rightarrow 6)-\beta$-D-glucosyl- $(1 \rightarrow 4)-D$ glucose. Judging from the fact that cellulase can specifically hydrolyze the glycosidic bonds between unbranched glucosyl residues and C-4 of 4,6-linked glucosyl residues, ${ }^{5,13,14)}$ $\mathrm{H}$-OS-Ib as well as $\mathrm{H}$-OS-II must have a $\mathrm{C}$-4substituted glucose residue at the reducing end and a C-6-substituted glucose residue at the non-reducing end of the glucan chain. Based on the results of methylation analysis and of fragmentation analysis of $\mathrm{H}$ OS-Ib, the structure of this nonasaccharide is proposed to be as follows;

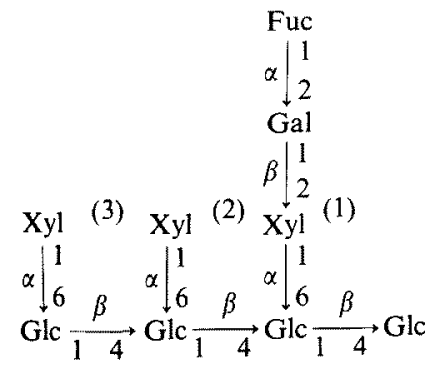

(H-OS-Ib)
It is considered that if a fucosylgalactosyl residue is linked to the second or third xylosyl residue (which is denoted as $\mathrm{Xyl}^{(2)}$ or $\mathrm{Xyl}^{(3)}$, respectively, in the above structure), $\mathrm{H}-\mathrm{OS}-\mathrm{Ib}$ must yield no isoprimeverose and no Fuc- $(1 \rightarrow$ 2)-Gal-(1 $\rightarrow 2)$-Xyl-( $1 \rightarrow 6)-G l c-(1 \rightarrow 4)-G l c$, but other kinds of oligosaccharides (Fuc- $(1 \rightarrow 2)$ Gal-(1 $\rightarrow 2)$-Xyl- $(1 \rightarrow 6)-G l c-[X y l-(1 \rightarrow 6)]-G l c-$ $(1 \rightarrow 4)$-Glc and others) on hydrolysis with $A s p$. oryzae $\beta$-glucosidase.

As shown in Table I, H-OS-Ia consisted of glucose, xylose, galactose and fucose in an approximate molar ratio of $4: 3: 2: 1$. When H-OS-Ia was subjected to carbon column (charcoal-Celite $(1: 1)$ ) chromatography, it was eluted as a single component from the column with $n$-butanol in water, a continuous gradient of 4 to $7 \% n$-butanol. H-OS-Ia was detected as a single component on paper chromatography (solvent system (A), descending). From these results, it was considered that H-OS-Ia was probably homogeneous. The results of methylation analysis of H-OS-Ia are shown in Table III. On hydrolysis with $A s p$. oryzae $\beta$-glucosidase, H-OS-Ia formed three saccharides; an oligosaccharide (Rglc 0.24), isoprimeverose and galactose in an approximate ratio of $2.1: 2.0: 0.5$ (weight). (Other spots between the origin and the Rglc 0.24 spot on the paper chromatogram (Fig. 3-(c)) seemed to be due to incomplete digestion.) The acid hydrolyzate of the oligosaccharide ( $\mathrm{Rglc}$ $0.24)$ gave glucose, xylose, galactose and fucose in a molar ratio of $2.0: 1.0: 1.1: 1.1$. For the reasons described above, it is reasonable to consider that this oligosaccharide is also $\alpha$-L-fucosyl- $(1 \rightarrow 2)-\beta$-D-galactosyl- $(1 \rightarrow 2)$ $\alpha-\mathrm{D}-\mathrm{x}$ y $\operatorname{los}$ y $1-(1 \rightarrow 6)-\beta-\mathrm{D}-\mathrm{g} 1 \mathrm{u}$ cos y $\mathrm{l}-$ $(1 \rightarrow 4)$-D-glucose. It was considered that the release of galactose from H-OS-Ia by the action of Asp. oryzae $\beta$-glucosidase was due to the concomitant action of $\beta$-galactosidase in the enzyme preparation. Therefore, it is probable that the non-reducing terminal galactose residue in H-OS-Ia (Table III) has the $\beta$-configuration. Based on the structures of H-OS-II and -Ib and the above results, the following structure is proposed for H-OS-Ia. 


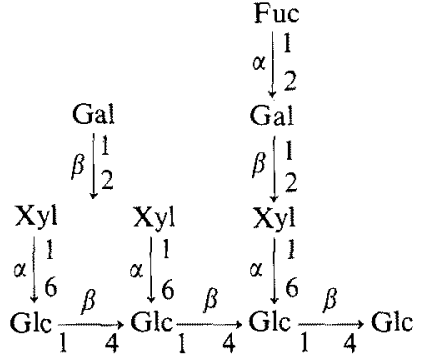

(H-OS-Ia)

Low molecular weight oligosaccharides fraction

\section{( $L-O S$ )}

From a mixture of low molecular weight oligosaccharides (L-OS), a trace amount of glucose and four kinds of oligosaccharides (LOS-1 to -4) were obtained after separation by preparative paper chromatography. The yields and general properties of L-OS- 1 to -4 are shown in Table IV. Figure 4 shows paper chromatograms of the hydrolyzates of L-OS-1 to -4 with $A s p$. oryzae $\beta$-glucosidase.

L-OS-1 having glucose and xylose in a molar ratio of $1: 1$ was chromatographically indistinguishable from authentic isoprimeverose (Fig. 4).

L-OS-2 consisted of glucose and xylose in an approximate molar ratio of $2: 1$ and the D.P. of this oligosaccharide was 3 (Table IV). Upon hydrolysis with $A s p$. oryzae $\beta$-glucosidase, LOS-2 yielded isoprimeverose and glucose (Fig. 4). L-OS-3 consisted of glucose and xylose in a molar ratio of $2.0: 1.8$ and the D.P. of the oligosaccharide was 4 (Table IV). On hy-

Table IV. Yields, Rglc Values, Degrees of Polymerization and Sugar Compositions of the Low Molecular Weight Oligosaccharides

\begin{tabular}{|c|c|c|c|c|c|c|c|}
\hline \multirow{2}{*}{ Oligosaccharide } & \multirow{2}{*}{$\begin{array}{l}\text { Yield } \\
(\mathrm{mg})\end{array}$} & \multirow{2}{*}{$\mathrm{Rglc}^{a}$} & \multirow{2}{*}{ D.P. } & \multicolumn{4}{|c|}{ Molar ratio of component sugars } \\
\hline & & & & Glc. & Xyl. & Gal. & Fuc. \\
\hline L-OS-4 & 5.6 & 0.24 & 5 & 5.0 & 2.9 & 1.2 & 0.9 \\
\hline L-OS-3 & 7.0 & 0.38 & 4 & 2.0 & 1.8 & & \\
\hline L-OS-2 & 4.2 & 0.54 & 3 & 2.0 & 0.8 & & \\
\hline L-OS-1 & 1.6 & 0.75 & 2 & 1.0 & 1.0 & & \\
\hline
\end{tabular}

(from $300 \mathrm{mg}$ of $\mathrm{MBXG}$ )

- Paper chromatography was carried out on Toyo No. 50 filter paper by a multiple ascending method (three times) with solvent system (A).

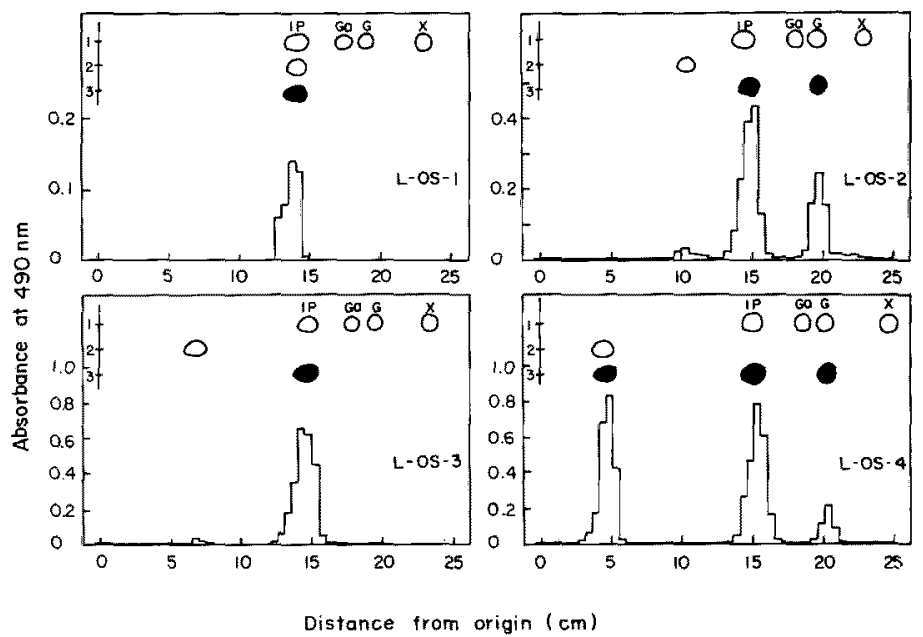

Fig. 4. Paper Chromatograms of the Hydrolyzates of L-OS-1 to -4 with $A s p$. oryzae $\beta$-Glucosidase. 1, authentic sugars; 2 , original oligosaccharide; 3 , hydrolyzate with Asp. oryzae $\beta$-glucosidase. IP, Ga, G and X indicate the positions of isoprimeverose, galactose, glucose and xylose, respectively. 
drolysis with $A s p$. oryzae $\beta$-glucosidase, it formed only isoprimeverose (Fig. 4). From these results, the structures of L-OS-2 and LOS-3 are proposed to be as follows:

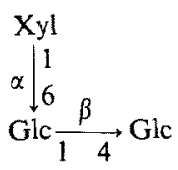

(L-OS-2)

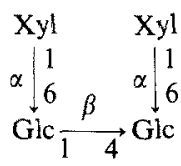

(L-OS-3)
L-OS-4 consisted of glucose, xylose, galactose and fucose in a molar ratio of $5.0: 2.9: 1.1: 0.9$ (Table IV). The $\beta$ glucosidase-hydrolyzate of L-OS-4 contained glucose, isoprimeverose and an unhydrolyzed oligosaccharide ( $\mathrm{Rglc} 0.24$ ) in an approximate ratio of $0.4: 2.4: 2.2$ (Fig. 4). The unhydrolyzed oligosaccharide gave glucose, xylose, galactose and fucose in an approximate molar ratio of $2.0: 0.8: 1.0: 0.9$ on acid hydrolysis. From the sugar composition and the Rglc value, it is reasonable to consider that the unhydrolyzed oligosaccharide is $\alpha$-L-fucosyl$(1 \rightarrow 2)-\beta$-D-galactosyl- $(1 \rightarrow 2)-\alpha$-D-xylosyl$(1 \rightarrow 6)-\beta-\mathrm{D}-\mathrm{glucosyl}-(1 \rightarrow 4)-\mathrm{D}-\mathrm{gluc}$ cose (OS-X, in the previous paper ${ }^{3)}$ ). Furthermore, the following structure is proposed for the oligosaccharide (L-OS-4A) which can be hydrolyzed by the $\beta$-glucosidase into isoprimeverose (two parts) and glucose (one

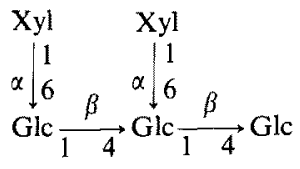

(L-OS-4A) part).

That is, it is concluded that L-OS-4 is composed of L-OS-4A and OS-X in a molar ratio of $1: 1$. The molar ratio of sugars constituting L-OS-4 is not contradictory to this conclusion.

\section{Structure of $M B X G$}

MBXG, when subjected to hydrolysis with $T$. viride cellulase, gave high molecular weight oligosaccharides (H-OS-Ia, -Ib and -II) and low molecular weight oligosaccharides (L-OS1 to -4$)$ in a ratio of $82: 18$. Because of the release of the low molecular weight oligosaccharides from MBXG on hydrolysis with the enzyme preparation, the following is highly likely: A part of the cellulase-derived high molecular weight oligosaccharides were further hydrolyzed into low molecular weight oligosaccharides during hydrolysis of MBXG with the enzyme preparation. It is, therefore, considered that MBXG molecules are made up of high molecular weight oligosaccharides, $\mathrm{H}$ OS-Ia, -Ib and -II. From the yields of H-OSIa, -Ib and -II (Table I), these oligosaccharides were calculated to occur in an approximate molar ratio of $1: 4: 4$. Thus the structure of MBXG is proposed to be as schematically shown in Fig. 5. The molar ratio of glucose, xylose, galactose and fucose based on the proposed structure is $10: 7.5: 1.7: 1.4$. These values are in fairly good agreement with those calculated from the complete acid hydrolyzate of MBXG (Glc : Xyl : Gal : Fuc $=10: 7: 2.5$ : 1). ${ }^{3)}$

Structures of xyloglucans from certain

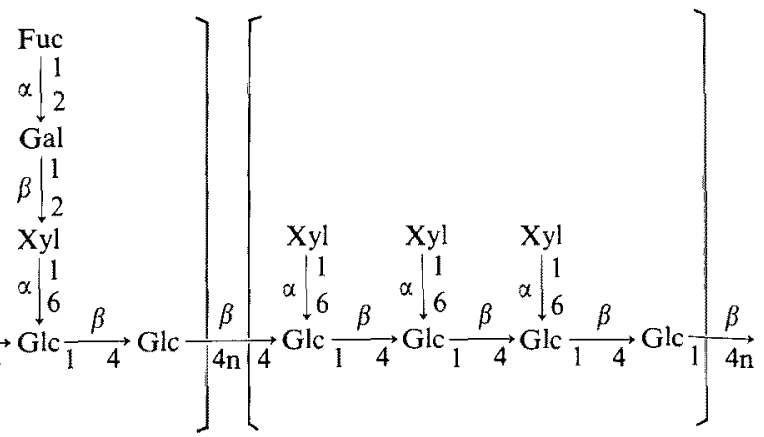

FIG. 5. Proposed Structure of MBXG. 
plants were characterized from the cellulasedegraded oligosaccharides. ${ }^{5,13 \sim 17)}$ One of the high molecular weight oligosaccharides, heptasaccharide, was found in xyloglucans of Tamarind, ${ }^{5}$ Red kidney bean ${ }^{15}$ ) and sycamore. ${ }^{13)}$ A nonasaccharide was also found in Red kidney bean and sycamore xyloglucans. However, the last high molecular weight oligosaccharide, decasaccharide, has not been found as yet in xyloglucans from any other source.

It is suggested that the method used for structural study of $\mathrm{MBXG}$ in the present paper involving two step-enzymatic degradation (cellulase and Asp. oryzae $\beta$-glucosidase) is quite useful for clarifying the structure of highly branched xyloglucans.

Acknowledgment. We thank Mr. Y. Kumagai of Morinaga Seika Co., Ltd. for supplying Glyloid 2A.

\section{REFERENCES}

1) Y. Kato and K. Matsuda, Plant and Cell Physiol, 17, 1185 (1976).

2) Y. Kato, N. Asano and K. Matsuda, ibid., 18, 821 (1977).
3) Y. Kato and K. Matsuda, Agric. Biol. Chem., 44, 1751 (1980).

4) K. N. Jones and R. J. Stoodly, "Methods in Carbohydrate Chemistry V," Academic Press, New York, 1965, p. 36.

5) P. Kooiman, Rec. Trav, Chim Pays-Bas, 80, 849 (1961).

6) Y. Kato, Doctor's thesis, Tohoku University, 1978, p. 53.

7) T. Hirayama, S. Horie, H. Nagayama and $K$. Matsuda, J. Biochem., 84, 27 (1978).

8) J. Robyt and D. French, Arch. Biochem. Biophys., 100, 451 (1963).

9) T. Imanari, Y. Arakawa and Z. Tamura, Chem. Pharm. Bull., 17, 1967 (1969).

10) S. Hakomori, J. Biochem. (Tokyo), 55, 205 (1964).

11) B. Lindberg, "Methods in Enzymology," Vol. 28 Academic Press, New York, 1972, p. 178.

12) M. Dubois, K. A. Gilles, J. K. Hamilton, P. A. Rebers and F. Smith, Anal. Chem., 28, 350 (1956).

13) D. Bauer, K. W. Talmadge, K. Keegstra and P. Albersheim, Plant Physiol., 51, 174 (1973).

14) M. Mori, S. Eda and K. Kato, Agric. Biol. Chem., 43, 145 (1979).

15) B. M. Wilder and P. Albersheim, Plant Physiol., 51, 889 (1973).

16) N. Shibuya and A. Misaki, Agric. Biol. Chem., 42, 2267 (1978).

17) J. M. Labavitch and P. M. Ray, Phytochemistry, 17, 933 (1978). 